BLS 35, No 1 2009. DOI: http://dx.doi.org/10.3765/bls.v35i1.3608

(published by the Berkeley Linguistics Society and the Linguistic Society of America)

\title{
Two Types of Covert Wh-movement
}

\author{
TAKAOMI KATO \\ Tokyo University of Science
}

\section{Introduction}

Noting some similarities in syntactic behavior between overtly moved wh-phrases and in-situ wh-phrases, Huang (1982) claimed that the latter also undergo whmovement, though covertly, or in LF. Within the Minimalist Program, at least three different ways of implementing Huang's insight have been proposed.

The first approach is to assume that an in-situ wh-phrase undergoes phrasal movement to SpecCP and its lower copy is pronounced at PF, as shown in (1) (cf. Chomsky 2004, Pesetsky 2000).

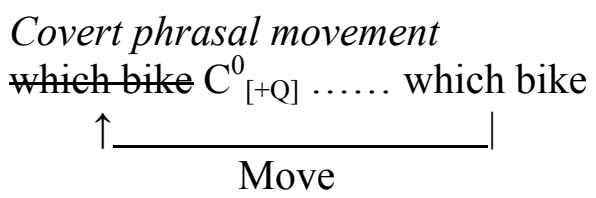

The higher copy and the lower copy of the wh-phrase are interpreted at LF as an operator and a variable, respectively.

The second approach is to assume that an in-situ wh-phrase does not move as a whole, but only the formal features of the wh-word undergo movement, adjoining to $\mathrm{C}^{0}$, as shown in (2) (cf. Chomsky 1995; "FF[which]" stands for formal features of which).

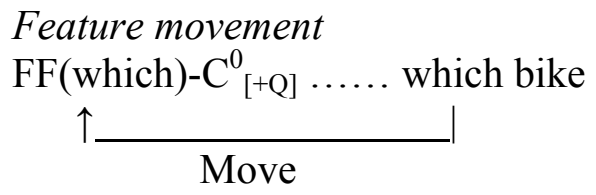

\footnotetext{
* I would like to thank the participants of Keio University Linguistics Colloquium (July, 2008) and BLS 35 for their helpful comments and questions. Part of this research was supported by a grant to the author from Japan Society for the Promotion of Science (Grant-in-Aid for JSPS Fellows, 191862).
} 


\section{Two Types of Covert Wh-movement}

The moved set of formal features is interpreted as an operator and its trace is interpreted as a variable at LF.

The third approach is to assume that an in-situ wh-phrase does not undergo any movement and is licensed through entering into an Agree relation with $\mathrm{C}^{0}$, as shown in (3) (cf. Chomsky 2000, 2001).

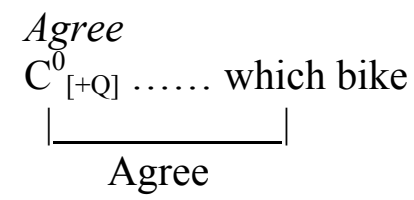

The $\mathrm{C}^{0}$ which is involved in the Agree relation and the in-situ wh-phrase are interpreted as an operator and a variable, respectively, at the LF interface.

The main aim of this paper is to claim that there are (at least) two different types of covert wh-movement which cannot be reduced to Agree. As far as we confine ourselves to the above-mentioned three approaches to $w h$-in-situ, this means that it is necessary to assume both phrasal and featural covert whmovement (cf. Pesetsky 2000).

The rest of this paper is organized as follows. In the next section, it is shown that in-situ echo wh-phrases may undergo covert phrasal movement, but in-situ non-echo $w h$-phrases cannot. In section 2, it is argued that in-situ non-echo whphrases are not licensed through Agree and undergo some sort of movement. From these results, it is concluded in the final section that there are (at least) two different types of covert wh-movement which cannot be reduced to Agree.

\section{Echo Questions vs. Non-Echo Questions}

As is well-known, in examples like (4) below, an R-expression contained within a fronted adjunct can be co-indexed with a pronoun which c-commands its original position (Freidin 1986, van Riemsdijk and Williams 1981).

$$
\text { [Which claim [that } \mathbf{J o h n}_{\mathbf{1}} \text { made]] was he } \mathbf{1} \text { willing to discuss? }
$$

(Chomsky 1993)

An interesting observation which concerns us here is that analogous binding effects obtain in echo questions (Kato 2004a, b, Rochemont and Culicover 1990). Thus, in the following example, the teacher, which is contained within a relative clause modifying an in-situ echo $w h$-phrase, can be co-indexed with her:

\section{Echo question}

Bill told her ${ }_{1}$ that Sam was dating [which student [that the teacher ${ }_{1}$ liked]]?

(Rochemont and Culicover 1990:168, note 18)

In order to account for why this example does not exhibit a Condition $\mathrm{C}$ effect, Rochemont and Culicover (1990) suggest that the relative clause in this ex- 
ample is (string-vacuously) extraposed and appears in the matrix clause, in a position higher than the matrix dative pronoun. There are several reasons to believe that this analysis is not plausible. One of them concerns the ungrammaticality of the following example (see Kato 2004a: note 15 for other reasons):

Non-echo question

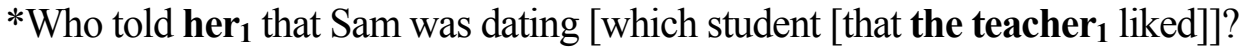

This example differs from (5) in that it is a regular, non-echo question. If the relative clause in (5) were extraposed to a position higher than the pronoun her, it would be mysterious why such extraposition is not available in (6).

For this and other reasons, Kato $(2004 a, b)$ claims that the contrast between (5) and (6) indicates that echo wh-phrases may undergo covert phrasal movement, but non-echo wh-phrases cannot. Suppose first that the in-situ wh-phrases in (5) and (6) undergo covert phrasal movement. Then, the LF representations of these examples should look like (7) below.

$$
\begin{aligned}
& \text { Covert phrasal movement } \\
& \text { [which student } \left.\ldots \text { the teacher }{ }_{1} \ldots\right] \mathrm{C}^{0}{ }_{[+\mathrm{Q}]} \ldots . . \text { her }_{1} \ldots .
\end{aligned}
$$

[which student ... the teacher $1 . .$.

In this representation, if the higher copy of the wh-phrase is somehow chosen to be interpreted at LF (against Chomsky's (1993) Preference Principle), no Condition $\mathrm{C}$ violation will be incurred. In contrast, if the in-situ wh-phrases at issue undergo featural movement or are licensed through Agree, the LF representations of the examples should be like (8) or (9).

\section{Featural movement}

$$
\mathrm{FF}(\text { which })-\mathrm{C}^{0}{ }_{[+\mathrm{Q}]} \ldots . . . \text { her }_{1} \ldots . .\left[\text { which student } \ldots \text { the teacher }{ }_{1} \ldots\right]
$$

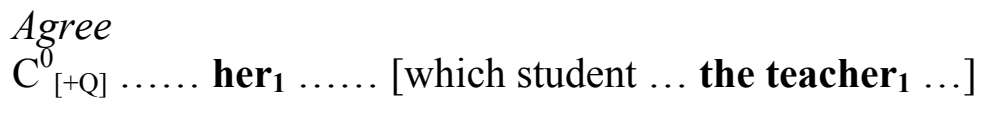

In these representations, there seems to be no way of the teacher obviating Condition C. Thus, the fact that example (5), but not example (6), satisfies Condition $\mathrm{C}$ indicates that echo $w h$-phrases, but not non-echo wh-phrases, can undergo covert phrasal movement.

Further evidence showing that echo wh-phrases may undergo the type of movement which is not available to non-echo wh-phrases comes from parasitic gap constructions. Consider the following examples:

Parasitic gap licensing

a. Overtly moved wh-phrase

Which paper did you file without reading $\mathbf{e}_{\mathbf{p g}}$ ? 


\section{Two Types of Covert Wh-movement}

\section{b. In-situ non-echo wh-phrase \\ *Who filed which paper without reading $\mathbf{e}_{\mathbf{p g}}$ ? \\ c. In-situ echo wh-phrase \\ ?You filed which paper without reading $\mathbf{e}_{\mathbf{p g}}$ ?}

These examples show that like overtly moved wh-phrases, in-situ echo whphrases can license a parasitic gap, but in-situ non-echo wh-phrases cannot (Kato 2004a, b).

To sum up, it has been shown in this section that echo wh-phrases may undergo covert phrasal movement but non-echo $w h$-phrases cannot.

\section{Wh-in-situ and CSC Effects}

What is given in (11) below is the well-known Coordinate Structure Constraint (CSC).

\section{Coordinate Structure Constraint (CSC; Ross 1967)}

In a coordinate structure, no conjunct may be moved, nor may any element contained in a conjunct be moved out of that conjunct.

It is clear that this constraint consists of two parts: the part which bans extraction of conjuncts, which accounts for the ungrammaticality of examples like (12a), and the part which bans extraction from conjuncts, which accounts for the ungrammaticality of examples like (12b).

\section{a. Extraction of a conjunct}

*What did Mary buy a bike and $t$ ?

b. Extraction from a conjunct

*What did Mary [send $t$ on Monday] and [receive the parcel on Wednesday]?

In what follows, I refer to the first part (or the ban on extraction of conjuncts) as the $\mathrm{CSC}_{\text {of }}$ and the second part (or the ban on extraction from conjuncts) as the $\mathrm{CSC}_{\text {from. }}$

It is argued by a number of researchers that the $\mathrm{CSC}_{\text {from }}$ is not a derivational constraint but a constraint on LF (or semantic) representations (cf., for example, Fox 2000, Kato 2006, Munn 1993; for arguments against the view that the $\mathrm{CSC}_{\text {from }}$ is a PF constraint, see Kato 2006: Chapter 5). In particular, Kato (2006) argues, following Fox (2000), that $\mathrm{CSC}_{\text {from }}$ effects of wh-questions should be attributed to an LF ban against vacuous quantification under the following assumptions:

a. A sentence with a coordinate structure is well-formed only if each of its component structures independently satisfies grammatical constraints. 
Takaomi Kato

b. Component structures of a sentence with a coordinate structure $=_{\text {def }}$ structures each of which is composed of one of the conjuncts together with the material which is not included by the coordinate structure ${ }^{1}$

Let us consider how the unacceptability of (12b), in which a wh-phrase is moved out of one of the two conjuncts, is dealt with under this approach. According to (13b), this example has the following two component structures:

\section{Component structures of (12b)}

a. what did Mary send $t$ on Monday

b. what did Mary receive the parcel on Wednesday

In one of these structures, $(14 \mathrm{~b})$, the wh-phrase fails to bind a variable, violating the ban on vacuous quantification. According to (13a), this is why the example is ill-formed.

Next, let us consider why example (15) below, where a wh-phrase is moved out of a coordinate structure in an across-the-board (ATB) manner, is acceptable:

\section{ATB movement}

What did Mary [send $t$ on Monday] and [receive $t$ on Wednesday]?

The two component structures of this example are the following:

\section{Component structures of (15)}

a. what did Mary send $t$ on Monday

b. what did Mary receive $t$ on Wednesday

Neither of these structures violates the ban on vacuous quantification (or any other grammatical constraints). Thus, the condition in (13a) correctly predicts that the example is acceptable.

A piece of evidence in favor of the LF representational approach to the $\mathrm{CSC}_{\text {from }}$ over the derivational approach comes from wh-in-situ (Fox 2000, Ruys 1993; see Kato 2006 and Lin 2001 for further evidence). Consider the following set of examples:

a. *I wonder who [took what from Mary] and [gave a book to Fred].

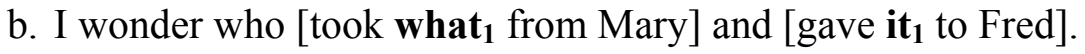

(Ruys 1993:36)

In both of these examples, the first conjunct contains an in-situ wh-phrase. The difference is that in the acceptable example, $(17 \mathrm{~b})$, a pronoun co-indexed with the in-situ $w h$-phrase appears in the second conjunct, while such a pronoun does not appear in the unacceptable example, (17a). If the $\mathrm{CSC}_{\text {from }}$ is a derivational con-

\footnotetext{
${ }^{1}$ See Kato (2008) for a slightly different definition of component structure.
} 


\section{Two Types of Covert Wh-movement}

straint on Move or Agree, the contrast between the above examples is unexpected: If movement of what out of the conjunct or its agreement with a head outside the conjunct is banned, (17b) should be ill-formed on a par with (17a).

In contrast, as argued by Fox (2000), the contrast in (17) is what the LF representational approach to the $\mathrm{CSC}_{\text {from }}$ predicts. First, consider the component structures of (17a). At LF, they should be represented as in (20), if the in-situ whphrase undergoes feature movement (cf. (18)), or as in (21), if it is licensed through Agree (cf. (19)).

$L F$ representation of (17a) (feature movement)

... FF(what $)_{1}-\mathrm{C}^{0}{ }_{[+\mathrm{Q}]}^{0}$ [took what ${ }_{1}$ from Mary] and [gave a book to Fred]

LF representation of (17a) (Agree)

$\ldots \mathbf{C}^{0}{ }_{[+\mathbf{Q} 11}\left[\right.$ took what ${ }_{1}$ from Mary] and [gave a book to Fred]

Component structures of (17a) (feature movement)

a. ... FF(what) $)_{1}-\mathrm{C}^{0}{ }_{[+\mathrm{Q}]}$ took what ${ }_{1}$ from Mary

b. ... FF(what) $)_{1}-\mathrm{C}_{[+\mathrm{Q}]}^{0}$ gave a book to Fred

Component structures of (17a) (Agree)

a. .... $\mathbf{C}^{\mathbf{0}}{ }_{[+\mathbf{Q}] 1}$ took what from Mary

b. ... $\mathbf{C}_{[+\mathbf{Q}] 1}^{0}$ gave a book to Fred

In either case, one of the component structures ((20b) or (21b)) involves vacuous quantification, hence the unacceptability of the example.

Next, consider the component structures of (17b), which should be like (22a, b) or $(23 a, b)$ below.

Component structures of (17b) (feature movement)

a. ... FF (what) ${ }_{1}-\mathrm{C}^{0}{ }_{[+\mathrm{Q}]}$ took what ${ }_{1}$ from Mary

b. ... FF(what) $)_{1}-\mathrm{C}_{[+\mathrm{Q}]}^{0}$ gave it $\boldsymbol{t}_{1}$ to Fred

Component structures of (17b) (Agree)

a. .... $\mathbf{C}_{[+\mathbf{Q}] 1}$ took what ${ }_{1}$ from Mary

b. ... $\mathbf{C}_{[+Q] 1}^{0}$ gave it to Fred

In each of these structures, no violation of the ban on vacuous quantification is incurred. In particular, this condition is satisfied in (22b) and (23b) because the operator binds the co-indexed pronoun as a variable there. Thus, the grammaticality of the example is correctly predicted. ${ }^{2}$

${ }^{2}$ For the unacceptability of examples like the following (Kasai 2004, Potts 2002), see Kato 2006: Appendix of Chapter 2.

(i) $*$ I wonder who [took it ${ }_{1}$ from Mary] and [gave what to $_{1}$ Fred]. 


\section{Takaomi Kato}

Now, let us turn to the $\mathrm{CSC}_{\text {of }}$, the ban on extraction of conjuncts. As shown in (24), wh-in-situ exhibits $\mathrm{CSC}_{\text {of }}$ effects, too ((24a) is adapted from Bošković and Franks 2000: footnote 4): ${ }^{3}$
a. *Mary wonders who reported that [who and Max] disappeared.
b. *Mary wonders who reported that the dog bit [who and Max].

However, unlike (17a) above, these examples cannot be rescued by adding a pronoun co-indexed with the wh-phrase to the second conjunct:

a. *Mary wonders who reported that [who 1 and his $\mathbf{w}_{\mathbf{1}}$ brother] disappeared.

b. *Mary wonders who reported that the dog bit [who 1 and his $\mathbf{s}_{\mathbf{1}}$ brother].

Given the above discussion, it follows from this fact that the ungrammaticality of the examples in (24) cannot be attributed (through (13)) to the LF ban against vacuous quantification, suggesting that the $\mathrm{CSC}_{\text {of }}$ is a derivational constraint (see Kato 2008: Appendix of Ch. 5 for more detailed discussion on the nature of the $\left.\mathrm{CSC}_{\mathrm{of}}\right)^{4}$

The fact that so-called "first conjunct agreement" is possible, as shown below, indicates that it is not Agree but Move that the $\mathrm{CSC}_{\text {of }}$ applies to (see Aoun et al. 1994, 1999, Munn 1999, among many others, for first conjunct agreement). ${ }^{5}$

\footnotetext{
${ }^{3}$ Some speakers judge examples like (i), where an in-situ $w h$-phrase appears as the second conjunct, to be acceptable or only slightly deviant (see Bošković and Franks (B\&F) 2000, Fiengo et al. 1988: 81, Reinhart 1997:339; for different judgments, see Bresnan 1975:37, Ginzburg 1992:171, Merchant 2001:200-201, footnote 16):
}

(i) Who reported that [Max and who] disappeared?

(B\&F 2000: 109)

Interestingly, B\&F, who judge (i) acceptable, observe the following contrast:

(ii) a. ?*[Who and Max $]_{1}$ did you report $t_{1}$ disappeared?

(ibid.: footnote 4)

b. [Max and who $]_{1}$ did you report $t_{1}$ disappeared?

(ibid.: 110)

Thus, here I assume (following B\&F) that some speakers can have recourse to covert pied-piping of the whole coordinate structure in examples like (i).

${ }^{4}$ It is reported by some researchers that violations of the $\mathrm{CSC}_{\text {of }}$ can be repaired under sluicing (though speakers' judgments do not seem to be clear; see Merchant 2001:193-4). This is not a problem for the view that the $\mathrm{CSC}_{\text {of }}$ is derivational in nature, if Boeckx (2008) and Wang (2007) are right in arguing that island-repair under ellipsis contexts is not directly related to the lack of pronunciation.

${ }_{5}^{5}$ Bošković (2007) also draws the same conclusion by contrasting "first conjunct movement" and "first conjunct agreement." However, his argument is less conclusive, because he does not take into consideration the possibility that the former may be ruled out by non-derivational constraints. His example intended to show the impossibility of movement of conjuncts is the following:

$$
\text { *A woman } 1 \text { is }\left[t_{1}\right. \text { and five men] in the garden. (Bošković 2007: (20)) }
$$




\section{Two Types of Covert Wh-movement}

First conjunct agreement

There is [a man and three children] at the front door.

Thus, the ungrammaticality of the examples in (24) indicates that in-situ (nonecho) wh-phrases undergo some sort of movement, not being licensed through Agree (otherwise, those examples should not exhibit the $\mathrm{CSC}_{\text {of }}$ effects).

\section{Conclusion}

In section 1, it was shown that in-situ echo wh-phrases may undergo covert phrasal movement, but in-situ non-echo $w h$-phrases cannot. In section 2 , it was argued that in-situ non-echo wh-phrases are not licensed through Agree and undergo some sort of movement. It follows from these results that there are (at least) two different types of covert $w h$-movement which cannot be reduced to Agree. If we confine ourselves to the three approaches to $w h$-in-situ mentioned in the introduction (namely covert phrasal movement, feature movement, and Agree), this means that we need to assume both phrasal and featural covert wh-movement.

Note that Pesetsky (2000) argues that at least two kinds of covert movementlike relations can be identified and that one of them is covert phrasal movement and the other is either feature movement or Agree. Crucially, he does not choose between the last two (see his p. 58). Thus, the present work could be seen as an elaboration of his argument.

\section{References}

Aoun, Joseph, Elabbas Benmamoun, and Dominique Sportiche. 1994. Agreement and conjunction in some varieties of Arabic. Linguistic Inquiry 25:195-220.

Aoun, Joseph, Elabbas Benmamoun, and Dominique Sportiche. 1999. Further remarks on first conjunct agreement. Linguistic Inquiry 30:669-681.

Boeckx, Cedric. 2008. Bare syntax. Oxford: Oxford University Press.

Bošković, Željko. 2007. Agree, phases, and intervention effects. Linguistic Analysis 33:54-96.

Bošković, Željko, and Steven Franks. 2000. Across-the-board movement and LF. Syntax 3:107-128.

In this example, as a result of the overt movement of a woman, the first conjunct of the coordinate structure is phonologically null. Thus, this example violates whatever PF constraint rules out examples like the following, where one of the conjuncts are deleted (cf. Grosu 1973, 1981, Merchant 2001):

(ii) a. *I couldn't lift this weight, but I know a boy who could [[ $\_$] and [lift a crowbar, too]]. (Grosu 1981: 53)

b. *I have five cats, but he has six [[dogs] and [ _ ]]! (Merchant 2001:196)

Note that the examples I give, (24a, b), satisfy the PF constraint at issue. 
Takaomi Kato

Bresnan, Joan. 1975. Comparative deletion and constraints on transformations. Linguistic Analysis 1:25-74.

Chomsky, Noam. 1993. A Minimalist Program for linguistic theory. In Kenneth Hale and Samuel Jay Keyser, eds., The view from Building 20: Essays in linguistics in honor of Sylvain Bromberger, 1-52. Cambridge, MA: MIT Press.

Chomsky, Noam. 1995. Categories and transformations. In Noam Chomsky, The Minimalist Program, 219-394. Cambridge, MA: MIT Press.

Chomsky, Noam. 2000. Minimalist inquiries. In Roger Martin, David Michaels and Juan Uriagereka, eds., Step by step: Essays on Minimalist syntax in honor of Howard Lasnik, 89-155. Cambridge, MA: MIT Press.

Chomsky, Noam. 2001. Derivation by phase. In Michael Kenstowicz, ed., Ken Hale, a life in language, 1-52. Cambridge, MA: MIT Press.

Chomsky, Noam. 2004. Beyond explanatory adequacy. In Adriana Belletti, ed., Structures and beyond: The cartography of syntactic structures, 104-131. Oxford: Oxford University Press.

Fiengo, Robert, C.-T. James Huang, Howard Lasnik, and Tanya Reinhart. 1988. The syntax of wh-in-situ. In Hagit Borer, ed., Proceedings of the Seventh West Coast Conference on Formal Linguistics, 81-98. Stanford, CA: CSLI.

Fox, Danny. 2000. Economy and semantic interpretation. Cambridge, MA: MIT Press.

Freidin, Robert. 1986. Fundamental issues in the theory of binding. In Barbara Lust, ed., Studies in the acquisition of anaphora, vol. 1, 151-188. Dordrecht: D. Reidel Publishing Company.

Ginzburg, Jonathan. 1992. Questions, queries and facts: A semantics and pragmatics for interrogatives. Ph.D. diss., Stanford University.

Grosu, Alexander. 1973. On the nonunitary nature of the Coordinate Structure Constraint. Linguistic Inquiry 4:88-92.

Grosu, Alexander. 1981. Approaches to island phenomena. Amsterdam: NorthHolland.

Huang, C.-T. James. 1982. Logical relations in Chinese and the theory of grammar. Ph.D. diss., Massachusetts Institute of Technology.

Kasai, Hironobu. 2004. Two notes on ATB movement. Language and Linguistics 5:167-188.

Kato, Takaomi. 2004a. Inaudible pre-spell-out movement. In Claire Bowern, ed., Harvard Working Papers in Linguistics 10, 75-100. Harvard University.

Kato, Takaomi. 2004b. Not so overt movement. In V. Chand, A. Kelleher, A.J. Rodríguez, and B. Schmeiser, eds., Proceedings of the 23rd West Coast Conference on Formal Linguistics, 436-449. Somerville, MA: Cascadilla Press.

Kato, Takaomi. 2006. Symmetries in coordination. Ph.D. diss., Harvard University.

Kato, Takaomi. 2008. Symmetries in coordination: The nature of the CSC and its implications. Ms., Sophia University.

Lin, Vivian. 2001. A way to undo A-movement. In Karine Megerdoomian and Leora Anne Bar-el, eds., Proceedings of the 20th West Coast Conference on Formal Linguistics, 358-371. Somerville, MA: Cascadilla Press. 


\section{Two Types of Covert Wh-movement}

Merchant, Jason. 2001. The syntax of silence: Sluicing, islands, and the theory of ellipsis. Oxford: Oxford University Press.

Munn, Alan. 1993. Topics in the syntax and semantics of coordinate structures. Ph.D. diss., University of Maryland, College Park.

Munn, Alan. 1999. First conjunct agreement: Against a clausal analysis. Linguistic Inquiry 30:643-668.

Pesetsky, David. 2000. Phrasal movement and its kin. Cambridge, MA: MIT Press.

Potts, Christopher. 2002. No vacuous quantification constraints in syntax. In Hirotani Masako, ed., Proceedings of the North East Linguistic Society 32, 451470. Amherst, MA: GLSA.

Reinhart, Tanya. 1997. Quantifier scope: How labor is divided between QR and Choice functions. Linguistics and Philosophy 20:335-397.

Rochemont, Michael and Peter Culicover. 1990. English focus constructions and the theory of grammar. Cambridge: Cambridge University Press.

Ross, John. 1967. Constraints on variables in syntax. Ph.D. diss., MIT. Published as Infinite syntax!, 1986, Norwood, NJ: Ablex.

Ruys, Eddy. 1993. The scope of indefinites. Ph.D. diss., Universiteit Utrecht.

van Riemsdijk, Henk, and Edwin Williams. 1981. NP structure. The Linguistic Review 1:171-217.

Wang, Chyan-an Arthur. 2007. Sluicing and resumption. In Emily Elfner and Martin Walkow, eds., Proceedings of the Thirty-seventh Annual Meeting of the North East Linguistic Society, Vol. 2, 239-251. Amherst, MA: GLSA.

Department of Liberal Arts

Faculty of Science Division I

Tokyo University of Science

1-3 Kagurazaka, Shinjuku-ku

Tokyo 162-8601

Japan

t-kato@rs.kagu.tus.ac.jp 